\title{
Evidence-based guidelines for the management of hypertension in children with chronic kidney disease
}

\author{
Janis M. Dionne
}

Received: 18 September 2014 /Revised: 3 February 2015 / Accepted: 17 February 2015 /Published online: 10 March 2015

(C) IPNA 2015

\begin{abstract}
Hypertension is common in children with chronic kidney disease and early evidence suggests that it is a modifiable risk factor for renal and cardiovascular outcomes. Recommendations for blood pressure management in children with chronic kidney disease can be found in various clinical practice guidelines including the 4th Task Force Report, the European Society of Hypertension pediatric recommendations, and the National Kidney Foundation Kidney Disease Outcomes Quality Initiative (K/DOQI) and Kidney Disease: Improving Global Outcomes (KDIGO) guidelines for the management of blood pressure in chronic kidney disease. Unfortunately, as pediatric trial evidence is limited, there are discrepancies in the recommendations that may lead to inconsistent clinical care and practice variation. This article reviews the strength of evidence behind each of the clinical practice guideline recommendations regarding blood pressure assessment, treatment targets, and first-line antihypertensive medications. The benefits and cautions of use of clinical practice guidelines are described with emphasis on the importance of reading beyond the summary statements.
\end{abstract}

Keywords Clinical practice guideline Clinic blood pressure . Ambulatory blood pressure monitoring $\cdot$ Target blood pressure $\cdot$ Treatment $\cdot$ Angiotensin-converting enzyme inhibitor $\cdot$ Angiotensin receptor blocker

\section{Introduction}

Hypertension is common in children with chronic kidney disease (CKD) and end-stage renal disease. In the CKD

\section{J. M. Dionne $(\triangle)$}

Division of Nephrology, Department of Pediatrics, University of

British Columbia, BC Children's Hospital, 4480 Oak Street,

Vancouver, BC V6H 3V4, Canada

e-mail: jdionne@cw.bc.ca population, prevalence rates vary from 48 to $54 \%$ from registry data and cohort studies [1,2]. Hypertension is a known independent risk factor for renal disease progression in children $[1,3,4]$. It is also a risk factor for left ventricular hypertrophy and increased carotid intima-media thickness in children with CKD [5-8]. There is even early evidence that treatment of hypertension can slow renal progression and reverse cardiovascular changes $[4,6,9]$. With mounting evidence that hypertension is a modifiable risk factor, it is important that we measure blood pressure, and diagnose and treat hypertension to prevent renal and cardiovascular consequences. Unfortunately, when we look for guidance on methods and goals from clinical practice guidelines, some of the recommendations are conflicting, especially where evidence is lacking.

The Institute of Medicine recognizes the importance of trustworthy clinical practice guidelines in physicians making informed decisions on patient care [10]. They have developed best practice standards to ensure high-quality recommendations (Table 1) [11]. Emphasis is placed on evaluating the quality of evidence through a systematic review and clearly reporting the strength of evidence behind the recommendation. The goal of a reliable clinical practice guideline is to optimize patient care and outcomes based on an evaluation of the potential benefits and harms of management options. The recommendations are intended for a specific clinical circumstance, not for generalizing, and are suggestions, not rules.

Recommendations for blood pressure management in children with CKD have been included in various guidelines. The 4th Task Force Report and the European Society of Hypertension (ESH) provide recommendations on general blood pressure management in pediatrics with comments about special populations including children with CKD $[12,13]$. The Fourth Report on the Diagnosis, Evaluation, and Treatment of High Blood Pressure in Children and Adolescents commissioned by the National Institutes of Health was published in 2004 
Table 1 Institute of Medicine standards for clinical practice guidelines

\begin{tabular}{ll}
\hline Standard & Content \\
\hline 1 & Establish transparency \\
2 & Manage conflict of interest \\
3 & Guideline development group composition \\
4 & Clinical practice guideline — systematic review \\
& intersection \\
5 & Establish evidence foundations for and rating \\
6 & strength of recommendations \\
7 & Articulation of recommendations \\
8 & External review \\
\hline
\end{tabular}

Reproduced from "Clinical practice guidelines we can trust: standards for developing trustworthy clinical practice guidelines," Institute of Medicine of the National Academy of Sciences [11]

[12]. This guideline reviewed new evidence that has arisen since the previously published report, Update on the Task Force Report, and included additional normative blood pressure data [14]. In 2009 ESH published guidelines on the Management of High Blood Pressure in Children and Adolescents [13]. Similar to the 4th Task Force Report, the guideline focus is general pediatric blood pressure management, with limited statements with regard to patients with renal disease (Table 2).

The National Kidney Foundation Kidney Disease Outcomes Quality Initiative (K/DOQI) developed guidelines for nondialysis $\mathrm{CKD}$ in an effort to encourage early intervention of modifiable risk factors in patients with CKD. With increasing evidence that hypertension was related to a more rapid decline in renal function in addition to early cardiovascular morbidity and mortality in adult CKD patients, they convened a working group and developed the Clinical Practice Guidelines on Hypertension and Antihypertensive Agents in

Table 2 European Society of Hypertension (ESH) recommendations for blood pressure management in children with chronic kidney disease

\begin{tabular}{ll}
\hline Area of management & Recommendation \\
\hline $\begin{array}{l}\text { What the blood pressure targets are: } \\
\text { chronic kidney disease }\end{array}$ & $\begin{array}{c}\text { Blood pressure below the } \\
\text { 75th percentile in children } \\
\text { without proteinuria, but } \\
\text { below the 50th percentile } \\
\text { in children with proteinuria }\end{array}$ \\
$\begin{array}{c}\text { It is reasonable at this time to } \\
\text { recommend agents blocking } \\
\text { special conditions: chronic } \\
\text { kidney disease }\end{array}$ & $\begin{array}{l}\text { the renin-angiotensin system } \\
\text { as first-line antihypertensive } \\
\text { medications in children with } \\
\text { and without proteinuria }\end{array}$
\end{tabular}

Modified from "Management of high blood pressure in children and adolescents: recommendations of the European Society of Hypertension" [13]
Chronic Kidney Disease [15]. The Work Group systematically reviewed the literature and incorporated an evidence grading system from A (strongest evidence) to $\mathrm{C}$ (weakest evidence) [15]. Guideline 13 is specifically for children with CKD, from birth through 18 years of age (Table 3).

The goal of Kidney Disease: Improving Global Outcomes (KDIGO) is to develop international evidence-based medicine clinical practice guidelines to improve patient care around the world. In 2012 they published a Clinical Practice Guideline for the Management of Blood Pressure in Chronic Kidney Disease [16]. They utilized a scoring system to evaluate the quality of evidence called the Grading of Recommendations Assessment, Development and Evaluation (GRADE) system, which is described in detail within the document [16]. In summary, each statement is given a strength of recommendation as level 1 ("we recommend") or level 2 ("we suggest") and quality of evidence letter from A (high) to D (very low). Within this guideline, no statements, pediatric or adult, were given a grade A recommendation and $19 \%$ of statements were not graded where evidence was not available [16]. Chapter 6

Table 3 Kidney Disease Outcomes Quality Initiative (K/DOQI) clinical practice guideline recommendations for blood pressure management in children with chronic kidney disease (CKD)

\begin{tabular}{ll}
\hline Guideline & Recommendation \\
\hline 13.1 & $\begin{array}{c}\text { Measurement of blood pressure in children should be } \\
\text { performed with age- and size-appropriate equipment, } \\
\text { and blood pressure values should be interpreted } \\
\text { according to normal values adjusted for age, gender, } \\
\text { and height percentile, as recommended by the 1996 } \\
\text { Update on the Task Force Report on High Blood } \\
\text { Pressure in Children and Adolescents: A Working } \\
\text { Group Report from the National High Blood Pressure } \\
\text { Education Program (A) } \\
\text { The cause of CKD and age of the child should be } \\
\text { considered in selecting the class of antihypertensive } \\
\text { agent (A) } \\
\text { Target blood pressure in children should be lower than } \\
\text { the 90th percentile for normal values adjusted for age, } \\
\text { gender, and height or 130/80 mmHg, whichever is } \\
\text { lower (B) } \\
\text { Because of the specialized nature of CKD and blood } \\
\text { pressure management in children, a pediatric kidney } \\
\text { disease specialist should be involved in their care, } \\
\text { when possible (C) }\end{array}$ \\
\end{tabular}

$\mathrm{A}=$ grade $\mathrm{A}$ recommendation - there is strong evidence that the practice improves health outcomes; $\mathrm{B}=$ grade $\mathrm{B}$ recommendation - there is moderately strong evidence that the practice improves health outcomes; $\mathrm{C}=$ grade $\mathrm{C}$ recommendation is based on either weak evidence or on the opinions of the Work Group and reviewers, that the practice may improve health outcomes

Reprinted from American Journal of Kidney Diseases, vol 43/no. 5, National Kidney Foundation, K/DOQI Clinical Practice Guidelines on Hypertension and Antihypertensive Agents in Chronic Kidney Disease, S1S290, Copyright 2004, with permission from Elsevier [15] 
provides recommendations for blood pressure management in children with CKD, from birth through 18 years of age (Table 4).

In this article, each guideline is reviewed with regard to the recommended method of blood pressure assessment, target blood pressure, and first-line antihypertensive medications. A review of the evidence behind the recommendations clarifies the strength of the evidence and illustrates the importance of reading the details behind the summary statements.

\section{Method of blood pressure measurement}

The first K/DOQI recommendation is that blood pressure should be measured with appropriately sized equipment based on evidence that the measurement technique is important for accurate readings [14]. The recommended method of blood pressure measurement is by auscultation in the 4th Task Force Report and the K/DOQI and KDIGO guidelines (Table 5). The K/DOQI Work Group recognized that 24-h ambulatory blood pressure monitoring (ABPM) seemed to correlate better with end organ damage, but stated that there was insufficient evidence for its routine use [15]. The KDIGO authors state that $\mathrm{ABPM}$ is useful in children with $\mathrm{CKD}$, but suggest that there might be insufficient evidence for routine recommendation and that the technology is not universally available [16].

Table 4 Kidney Disease: Improving Global Outcomes (KDIGO) clinical practice guideline recommendations for blood pressure management in children with chronic kidney disease (CKD)

Guideline Recommendation

6.1 We recommend that in children with CKD ND, blood pressure-lowering treatment is started when blood pressure is consistently above the 90th percentile for age, sex, and height (1C)

We suggest that in children with CKD ND (particularly those with proteinuria), blood pressure is lowered to consistently achieve systolic and diastolic readings less than or equal to the 50th percentile for age, sex, and height, unless achieving these targets is limited by signs or symptoms of hypotension (2D)

We suggest that an ARB or ACE-I be used in children with CKD ND in whom treatment with blood pressurelowering drugs is indicated, irrespective of the level of proteinuria (2D)

$1 \mathrm{C}=$ we recommend that most patients should receive the course of action; quality of evidence is low; $2 \mathrm{D}=$ we suggest considering the course of action, but different choices will be appropriate for different patients; quality of evidence is very low

Reproduced with permission from KDIGO [16]

$C K D N D$ non-dialysis-dependent chronic kidney disease, $A R B$ angiotensinreceptor blocker, $A C E-I$ angiotensin-converting enzyme inhibitor
The strength of evidence for use of ABPM in children with CKD is mounting. Early ABPM studies demonstrated blood pressure abnormalities and distorted circadian blood pressure rhythms in children with kidney disease [17]. Further studies have confirmed blood pressure abnormalities only identifiable with ABPM, including nocturnal hypertension, night-time nondipping, and masked hypertension [18-21]. ABPM shows improved consistency and reproducibility of blood pressure readings in children [22, 23]. Even end-organ damage, evaluated by left ventricular mass, correlates more closely with ABPM than clinic blood pressure measurements [20, 24].

The ESH guideline recommends blood pressure measurement by auscultation for the general pediatric patient, but 24-h ABPM for children with CKD [13]. So why is there a discrepancy between guidelines? Part of the answer may lie in timing, as an essential trial on blood pressure management in children with CKD using ABPM, the ESCAPE trial, was published in 2009, after the 4th Task Force Report and K/DOQI guidelines [4]. The other contributing factor is the feasibility of programs to provide routine ABPM. In Europe, during the ESCAPE trial, almost 400 children across 13 countries, at 33 nephrology centers, performed ABPM every 6 months for 5 years, demonstrating well-established programs for ABPM. The KDIGO recommendations are intended to be global and are cautious with regard to ABPM, which may not be available in all countries. This could create inequality where centers without ABPM programs would be unable to meet standards.

\section{Normative references}

All guidelines recognize that clinic blood pressure measurement by auscultation should be compared with the most up-todate Task Force blood pressure tables according to gender, age, and height percentile. Observational and epidemiological data, in addition to previous Task Force guidelines, show that in children blood pressure increases with age and size [14, 25]. The 4th Task Force Report incorporated new National Health and Nutrition Examination Survey (NHANES) data into the revised blood pressure tables and identified the 50th, 90th, 95th, and 99th blood pressure percentiles. The reference values were determined by statistical analysis of blood pressure measurements of more than 60,000 children in the USA, with $54 \%$ of Caucasian, $29 \%$ of African-American, and $10 \%$ of Hispanic ethnicity [12].

The normative ABPM values referenced in the ESH guideline are the normalized ABPM tables from the German Working Group on Pediatric Hypertension [26]. Based on ABPM readings analyzed from almost 1,000 children, they include reference values for children taller than $120 \mathrm{~cm}$. The standards are often criticized, as they are based solely on a Caucasian population, but are likely very applicable to many European countries. In general, guidelines recommend the best 
normative reference available at the time of the publication, but clinicians with a patient in front of them need to consider if the reference is most fitting for their patient or if there are newer or local standards that would be more appropriate.

\section{Blood pressure for initiation of treatment}

The KDIGO clinical practice guideline is the first guideline to suggest a target for treatment initiation (Table 5). They recommend the initiation of antihypertensive medication when the blood pressure is consistently above the 90th percentile for gender, age, and height (Table 4). The authors refer to other guidelines, including the 4th Task Force Report, K/DOQI blood pressure guidelines, and the American Heart Association guideline on Cardiovascular Risk Reduction in High-Risk Pediatric Patients [12, 15, 27]. The recommended initiation target is an extrapolation of the treatment targets of the other guidelines. The KDIGO authors refer to evidence from the observational cohort CKiD study from an abstract showing that clinic blood pressure above the 90th percentile was associated with a more rapid progression of CKD compared with lower blood pressure, although results were not statistically significant [28]. In addition, unpublished data from the randomized controlled ESCAPE trial showed lower kidney survival when systolic or diastolic blood pressure was above the 90th percentile compared with lower blood pressure [16]. The KDIGO recommendation for treatment initiation at a blood pressure above the 90th percentile seems entirely reasonable, but from a strict evidence-based medicine point of view, is based on extrapolations from previous guidelines and preliminary and unpublished data.

\section{Blood pressure treatment target}

Both the 4th Task Force Report and the K/DOQI blood pressure guidelines recommend treating to a target of less than the 90th percentile blood pressure in children with CKD (Table 5). Unfortunately, neither recommendation is based on strong evidence. Specifically, the 4th Task Force Report states that the treatment blood pressure goal should be less than the 95th percentile in otherwise healthy children, but less than the 90th percentile in children with CKD, diabetes, or target organ damage [12]. This recommendation comes from extrapolation from the adult JNC 7 report [29]. The K/DOQI recommendation is that the target blood pressure should be less than the 90th percentile or less than $130 / 80 \mathrm{mmHg}$, whichever is lower (Table 3). The evidence for this statement comes from other guidelines; the Update on the Task Force Report, the British Renal Association guideline, and the adult $\mathrm{K} / \mathrm{DOQI}$ recommendations $[14,15,30]$. Interestingly, the 1996 Update on the Task Force Report suggests targeting less 
than the 95th percentile in children with renal disease and the 90th percentile only in children with diabetes [14]. Even the adult section of the K/DOQI blood pressure guideline, which recommends a target of less than $130 / 80 \mathrm{mmHg}$, is based on the extrapolation of adult studies of patients with diabetes and congestive heart failure, with scant evidence in patients with CKD [15]. The guideline does recognize that there is insufficient information available on the optimal blood pressure target for children and adults with CKD.

The ESH guideline target blood pressure recommendation is to aim for a mean arterial pressure (MAP) by ABPM of less than the 75 th percentile in children with CKD, but if proteinuria is present, aim for less than the 50th percentile (Table 2). The evidence behind the statement comes from one randomized controlled study, the ESCAPE trial, which was preliminary and not yet published at the time of this guideline [4]. The ESCAPE trial was designed to compare intensified blood pressure control (target $<50$ th percentile) with conventional control (50th to 90th percentile) in children with CKD on a fixed dose of angiotensin-converting enzyme (ACE) inhibitor [4]. The outcome measure of CKD progression was defined as a $50 \%$ reduction in estimated glomerular filtration rate (eGFR) by the Schwartz formula, eGFR less than $10 \mathrm{ml} /$ $\mathrm{min} / 1.73 \mathrm{~m}^{2}$ or a need for renal replacement therapy. Based on information from an abstract, patients who achieved a MAP less than the 75th percentile had improved renal survival compared with those who exceeded this target [13]. The lower target of the 50th percentile improved renal survival only in children with baseline proteinuria.

Further details of the ESCAPE trial are now available, with the final publication of the article [4]. What is learned is that the analysis was confounded by the fact that more than half of the patients in the conventional blood pressure group inadvertently reached the target for the intensified blood pressure group. A post-hoc analysis of achieved blood pressure showed a statistical and clinical improvement in renal survival by achieving a MAP below the 75th and 50th percentiles [4]. The benefits of intensified blood pressure control were seen in subgroups of children, including those with a baseline eGFR of $<45 \mathrm{ml} / \mathrm{min} / 1.73 \mathrm{~m}^{2}$, an annualized loss of eGFR of $>3 \mathrm{ml}$ per year before study entry, a baseline 24-h MAP above the 90th percentile, and proteinuria $>1.5 \mathrm{mg} / \mathrm{mg}$ creatinine. A reduction in proteinuria of $50 \%$ within the first 2 months of ACE inhibition was predictive of renal survival. This demonstrates that studies of clinical importance to potentially change practice should be critically reviewed to understand the details of what the study can show.

The blood pressure treatment target recommended by KDIGO for children with CKD is systolic and diastolic blood pressure less than the 50th percentile for gender, age, and height (Table 4). The primary evidence upon which this statement is based comes from the ESCAPE trial and the related ESH guideline recommendation $[4,13]$. The issue with this target is that the European blood pressure targets are based on 24-h MAP by ABPM, which may or may not be equivalent to a 50th percentile clinical blood pressure, as recommended by the KDIGO guideline. Evidence based on clinical blood pressure targets comes only from an abstract from the CKiD study showing a slower rate of kidney disease progression with blood pressures below the 50th percentile compared with higher values [28]. The KDIGO recommendation does caution against aggressive achievement of the low blood pressure target in all children with CKD, as patients with polyuria or frequent dehydration episodes are more likely to develop hypotension and acute kidney injury [16]. They also comment that clinicians need to balance the risks of polypharmacy if blood pressure is difficult to control against the potential benefits of limiting kidney disease progression.

\section{First-line antihypertensive medication}

All of the clinical guidelines are in agreement in recommending ACE inhibitors or angiotensin-receptor blockers (ARBs) as first-line antihypertensive medications for children with CKD (Table 5). This is despite the limited strength of evidence available for their benefit in pediatric CKD. In the earliest guideline reviewed here, the 4th Task Force Report recommends use of ACE inhibitors in children with diabetes and albuminuria or renal diseases with proteinuria. These recommendations come from extrapolations from the adult JNC 7 report [29].

The K/DOQI guideline suggests consideration of the child's age and underlying cause of CKD when choosing a class of antihypertensive medication (Table 3). Many pharmacological studies and case series provide evidence that blood pressure medications in children need to be dose-adjusted based on age and size because of differences in metabolism and drug effects $[14,15,31]$. As the use of diuretics is common in adults with hypertension, the Work Group suggests that while diuretics may be appropriate in children with salt and water retention, they might not be advisable in children with a tubulopathy and salt-wasting, such as can occur with an obstructive uropathy or renal dysplasia $[15,30]$. They suggest that ACE inhibitors or ARBs should be considered the first-line antihypertensive medications to slow the rate of progression of renal disease, although note that the supporting evidence is weak [15]. Four small nonrandomized trials showed that ACE inhibitors or ARBs could reduce proteinuria in children with renal disease [32-35]. The studies were uncontrolled except for one small placebo cross-over study [33]. However, the Work Group cautions against the use of ACE inhibitors in neonates owing to the increased risk of side effects and in premature infants because of the importance of the renin-angiotensin system in normal renal development [36-38]. 
The ESH guideline recommends the use of ACE inhibitors and ARBs as first-line antihypertensive medication in children with proteinuric and non-proteinuric CKD (Table 2). The ESCA $\mathrm{PE}$ trial showed that patients who had a significant reduction in proteinuria on fixed-dose ACE inhibitor had less renal disease progression [4]. From a strict evidence-based medicine perspective, the trial was designed to compare blood pressure targets and all subjects received a fixed dose ACE inhibitor, so to conclude that proteinuria reduction (and ACE inhibitors) were responsible for better outcomes, this analysis would need to be adjusted for blood pressure achieved. Two additional small uncontrolled studies and one systematic review in children with CKD also showed reduction in hypertension and proteinuria, with agents blocking the renin-angiotensin system [39-41]. More importantly, while only a small study, one controlled trial, compared an ARB with a calcium channel blocker in children with $\mathrm{CKD}$ and found a similar reduction in blood pressure with both agents, but a greater reduction in proteinuria with the ARB [42]. The ESH authors caution against the use of combination ACE inhibitors and ARBs because of the adult ONTARGET study, where no benefit was shown for combination therapy over monotherapy, but combined therapy was associated with increased adverse events [43].

Consistent with other guidelines, the KDIGO authors recommend that ARBs or ACE inhibitors be used as first-line antihypertensive medications in children with CKD (Table 4). Additional evidence for this recommendation comes from cross-sectional studies from the CKiD trial and several small trials in children with CKD [16]. Analysis of baseline blood pressure of participants in the CKiD study showed higher use of ACE inhibitors and ARBs in children with controlled hypertension [2]. In addition, use of ACE inhibitors or ARBs was associated with lower baseline urine protein excretion in children with CKD owing to glomerular, but not hypodysplasia causes in the CKiD study [44]. The lack of effect of renin-angiotensin system blockers on CKD progression in children with hypodysplasia was also seen in a case-control study by the ItalKid Project [45]. In the ESCA $\mathrm{PE}$ trial, intensified blood pressure control did slow disease progression in children with hypodysplasia, but the study was not designed to attribute the outcomes to ACE inhibitor use specifically [4]. A small randomized double blind cross-over trial in children with proteinuric renal disease demonstrated a similar reduction in proteinuria with ACE inhibitor compared with ARB, a finding that has been confirmed with a more recent larger trial $[46,47]$. Combined use of ACE inhibitors and ARBs has shown additional reduction in proteinuria with both agents in two small studies in children $[48,49]$. The KDIGO authors caution that risks of renin-angiotensin system blockers include hypotension in susceptible individuals, hyperkalemia, acute kidney injury during dehydrating illness, and teratogenicity if pregnancy occurs [16]. They suggest an individualized approach, which is always a wise recommendation when dealing with a population with a wide age range and underlying disease of various etiologies.

\section{Practical clinical management suggestions}

Limited evidence and sometimes conflicting recommendations can leave practitioners at a loss of how to best manage their patients. Balancing the risk of providing yet another recommendation based on little evidence, I attempt to provide practical considerations. If a practitioner's medical center has, or can establish, an ABPM program, then routine ABPM every 6-12 months will likely provide them with a wealth of blood pressure information, including diagnosing masked hypertension and nocturnal blood pressure abnormalities. If ABPM is not available or between studies, proper clinic assessment of blood pressures will likely still be of benefit. There is no specific evidence to suggest a blood pressure threshold for initiation of antihypertensive medications, but consistent readings above the 90th percentile seem reasonable. Others may argue that if our treatment goal is lower, why wait? Treatment targets for blood pressures by auscultation have not been established, but aiming for values between the 50th and 75th percentile, as tolerated, would unlikely be disputed. At this time, best evidence suggests that the ABPM treatment target in lower-risk CKD patients should be the 75th percentile for MAP, but should be below the 50th percentile in higher risk patients, including those with proteinuria, rapid progression, lower GFR, and higher initial blood pressure. Most pediatric and adult evidence points to ACE inhibitors or ARBs as the best initial antihypertensive medication when tolerated. These suggestions will need reevaluation as newer evidence is discovered.

\section{Benefits of guidelines}

The ultimate goal of clinical practice guidelines is to consolidate evidence for management options to improve the care provided to patients by medical practitioners. Even in subspecialty pediatric medicine, physicians cannot be experts on all diseases within their scope of care. Effective guidelines are able to provide evidence-based recommendations where available to guide and potentially improve patient care. They can also reduce clinical practice variation among and within medical centers. Where strong evidence for a management option is lacking, the guideline can provide an expert opinion. In clinical practice when physicians encounter a situation where they need advice, they may ask their colleagues, post a query on a list-server, send an email to "ask an expert," or similarly, search for a relevant clinical practice guideline. 


\section{Cautions with guidelines}

There are limitations on the interpretation and use of clinical practice guidelines. The information included in the systematic review is up to date only to the time of publication and needs to be regularly reviewed and updated (Table 1). A guideline published 10 years earlier may not still be applicable to current day practice. Discrepancies between guidelines can create confusion and inconsistent clinical care as practitioners try to decide which recommendation to follow. As highlighted by the Institute of Medicine criteria for trustworthy guidelines, the statements are intended for a specific clinical circumstance and therefore the practitioner must determine if they apply to the patient in front of them [10]. There is also concern when practice guidelines are published that hospital administrators might misinterpret the recommendations as clinical performance measures without paying attention to the strength, or lack, of evidence behind the statements.

One criticism of clinical practice guidelines is that recommendations are still made, even where quality of evidence is low. This must be balanced with providing too strict an evidence-based medicine evaluation that limits any meaningful guidance from being provided. The recent US Preventive Services Task Force (USPSTF) statement on screening asymptomatic children for primary hypertension to prevent future cardiovascular disease concluded that there was insufficient evidence to recommend routine blood pressure screening [50]. Unfortunately, this strict evidence-based analysis that concludes that there is a lack of large-scale, high-quality, longterm studies to demonstrate a benefit, has been misinterpreted to mean there is evidence for no benefit [51]. In contrast, based on evidence from shorter term studies and less severe outcomes (e.g., childhood left ventricular hypertrophy instead of adult cardiovascular disease), expert panels and professional organizations, including the American Academy of Pediatrics, European Society of Hypertension, and American Society of Pediatric Nephrology, recommend the benefits of measuring blood pressure in children to detect and treat identified hypertension [13, 52-54]. The decision to provide strict evidence-based recommendations or include suggestions based on expert opinion should be decided before the systematic review. Thus, while it is tempting to read only the bolded summary statements before making patient decisions, it is important to understand the work group's intended use of the clinical practice guideline, and the strength of the evidence behind the recommendations, so that the practitioner can make their own informed decision.

\section{Future research recommendations}

There is still a strong need for further research on blood pressure management in children with CKD. To start with, normative reference values for ABPM in populations that include various ethnicities are needed, although research is beginning in this area [55]. Very little is known about when to initiate antihypertensive medications. The only published trial on target blood pressure during treatment in children with CKD is the ESCAPE trial, which needs to be confirmed. A placebo controlled trial or non-ACE inhibitor arm study would be difficult to justify currently, but if research from observational trials or reviews of practice variation were to suggest opposing results, then there may be the potential of clinical equipoise to justify another trial. The pediatric nephrology community is learning the importance of cooperation when trying to answer some of these challenging questions, as the best answers come from well-designed multicenter, multi-national studies with the ultimate benefit for the children we care for.

\section{Conclusion}

Recommendations for blood pressure management in children with CKD can be found in various clinical practice guidelines, including the 4th Task Force Report, ESH pediatric recommendations, K/DOQI hypertension guideline, and the KDIGO blood pressure management guideline $[12,13,15,16]$. As there are few studies in pediatric CKD to provide evidence for the recommendations, suggestions vary between guidelines on whether to use clinic blood pressure measurements or ABPM and what blood pressure goal to target with treatment. This highlights the importance for users of clinical practice guidelines to understand the strength of evidence upon which the recommendations are made. Good clinical practice guidelines can reduce practice variation and improve the care provided to patients. Statements based on expert opinion may still be of use to a practitioner who needs guidance, but also serve to define important areas for further research so that the next iteration of the guideline may be based on a stronger level of evidence.

\section{Multiple choice questions (answers are provided following the reference list)}

1. Recommendations for blood pressure management in children with CKD are based on some pediatric evidence for all of the guidelines below, except:

a) 4th Task Force Report

b) European Society of Hypertension guideline

c) $\mathrm{K} / \mathrm{DOQI}$ hypertension guideline

d) KDIGO blood pressure management guideline

2. The recommended method of blood pressure measurement in children with CKD is by auscultation of clinic blood pressure for all of the guidelines below except: 

a) 4th Task Force Report
b) European Society of Hypertension guideline
c) $\mathrm{K} / \mathrm{DOQI}$ hypertension guideline
d) KDIGO blood pressure management guideline

3. The only clinical practice guideline to recommend a blood pressure target for the initiation of antihypertensive medication is:
a) 4th Task Force Report
b) European Society of Hypertension guideline
c) $\mathrm{K} / \mathrm{DOQI}$ hypertension guideline
d) KDIGO blood pressure management guideline

4. Which of the following statements regarding good clinical practice guidelines is false?

a) Is based on a thorough systematic review of current evidence

b) Provides ratings for the strength of recommendation and quality of evidence

c) If well written, can provide recommendations for practitioners to follow in clinical practice for the following decade

d) Is based on a transparent process for development, with documentation of potential conflicts of interest

5. Which of the following statements on the benefits and cautions regarding clinical practice guidelines is false?

a) When translated into clinical practice, can reduce practice variation amongst practitioners

b) May be used inappropriately by hospital administrators to create clinical performance measures

c) There is no benefit to a recommendation based only on expert opinion

d) Statements are intended for a specific clinical situation and are not meant to be generalized

\section{References}

1. Mitsnefes M, Ho P, McEnery P (2003) Hypertension and progression of chronic renal insufficiency in children: a report of the North American Pediatric Renal Transplant Cooperative Study (NAPRTCS). J Am Soc Nephrol 14:2618-2622

2. Flynn J, Mitsnefes M, Pierce C, Cole S, Parekh R, Furth S, Warady B (2008) Blood pressure in children with chronic kidney disease: a report from the Chronic Kidney Disease in Children Study. Hypertension 52:1-7

3. Wingen A, Fabian-Bach C, Schaefer F, Mehls O, for the European Study Group for Nutritional Treatment of Chronic Renal Failure in Childhood (1997) Randomised multicentre study of a low-protein diet on the progression of chronic renal failure in children. Lancet 349:1117-1123

4. The ESCAPE Trial Group (2009) Strict blood-pressure control and progression of renal failure in children. N Engl J Med 361:1639-1650
5. Mitsnefes M, Kimball T, Kartal J, Witt S, Glascock B, Khoury P, Daniels S (2006) Progression of left ventricular hypertrophy in children with early chronic kidney disease: 2-year follow-up study. J Pediatr 149:671-675

6. Kupferman J, Friedman A, Cox C, Flynn J, Furth S, Warady B, Mitsnefes M (2014) BP control and left ventricular hypertrophy regression in children with CKD. J Am Soc Nephrol 25:167-174

7. Brady T, Schneider M, Flynn J, Cox C, Samuels J, Saland J, White C, Furth S, Warady B, Mitsnefes M (2012) Carotid intima-media thickness in children with CKD: results from the CKiD study. Clin J Am Soc Nephrol 7:1930-1937

8. Litwin M, Wuhl E, Jourdan C, Niemirska A, Schenk J, Jobs K, Grenda R, Wawer Z, Rajszys P, Mehls O, Schaefer F (2008) Evolution of large-vessel arteriopathy in paediatric patients with chronic kidney disease. Nephrol Dial Transplant 23:2552-2557

9. Matteucci M, Chinali M, Rinelli G, Wuhl E, Zurowska A, Charbit M, Pongiglione G, Schaefer F (2013) Change in cardiac geometry and function in CKD children during strict $\mathrm{BP}$ control: a randomized study. Clin J Am Soc Nephrol 8:203-210

10. Greenfield S, Steinberg E, for the Institute of Medicine Committee on Standards for Developing Trustworthy Clinical Practice Guidelines (2011) Clinical practice guidelines we can trust: Report Brief. Available at www.iom.edu/cpgstandards

11. Institute of Medicine of the National Academies (2011) Clinical practice guidelines we can trust: Standards for developing trustworthy clinical practice guidelines (CPGs). Available at www.iom.edu/ cpgstandards

12. National High Blood Pressure Education Program Working Group on High Blood Pressure in Children and Adolescents (2004) The fourth report on the diagnosis, evaluation, and treatment of high blood pressure in children and adolescents. Pediatrics 114:555-576

13. Lurbe E, Cifkova R, Cruickshank J, Dillon M, Ferreira I, Invitti C, Kuznetsova T, Laurent S, Mancia G, Morales-Olivas F, Rascher W, Redon J, Schaefer F, Seeman T, Stergiou G, Wuhl E, Zanchetti A (2009) Management of high blood pressure in children and adolescents: recommendations of the European Society of Hypertension. J Hypertens 27:1719-1742

14. National High Blood Pressure Education Program Working Group on Hypertension Control in Children and Adolescents (1996) Update on the 1987 Task Force Report on High Blood Pressure in Children and Adolescents: a working group report from the National High Blood Pressure Education Program. Pediatrics 98:649-658

15. National Kidney Foundation (2004) K/DOQI clinical practice guidelines on hypertension and antihypertensive agents in chronic kidney disease. Am J Kidney Dis 43:S1-S290

16. Kidney Disease: Improving Global Outcomes (KDIGO) Blood Pressure Work Group (2012) KDIGO clinical practice guideline for the management of blood pressure in chronic kidney disease. Kidney Int Suppl 2:337-414

17. Lingens N, Freund M, Seeman T, Witte K, Lemmer B, Scharer K (1997) Circadian blood pressure changes in untreated children with kidney disease and conserved renal function. Acta Paediatr 86:719-723

18. Mitsnefes M, Kimball T, Daniels S (2003) Office and ambulatory blood pressure elevation in children with chronic renal failure. Pediatr Nephrol 18:145-149

19. Dionne J, Turik M, Hurley R (2008) Blood pressure abnormalities in children with chronic kidney disease. Blood Press Monit 13:205-209

20. Mitsnefes M, Flynn J, Cohn S, Samuels J, Blydt-Hansen T, Saland J, Kimball T, Furth S, Warady G, for the CKiD Study Group (2010) Masked hypertension associates with left ventricular hypertrophy in children with CKD. J Am Soc Nephrol 21:137-144

21. Samuels J, Ng D, Flynn J, Mitsnefes M, Poffenbarger T, Warady B, Furth S, for the Chronic Kidney Disease in Children Study Group (2012) Ambulatory blood pressure patterns in children with chronic kidney disease. Hypertension 60:43-50 
22. Lurbe E, Redon J (2002) Reproducibility and validity of ambulatory blood pressure monitoring in children. Am J Hypertens 15:69S-73S

23. Gimpel C, Wuhl E, Arbeiter K, Drozdz D, Trivelli A, Charbit M, Gellermann J, Dusek J, Jankauskiene A, Emre S, Schaefer F, for ESCAPE Trial Group (2009) Superior consistency of ambulatory blood pressure monitoring in children: implications for clinical trials. J Hypertens 27:1568-1574

24. Sorof J, Cardwell G, Franco K, Portman R (2002) Ambulatory blood pressure and left ventricular mass index in hypertensive children. Hypertension 39:903-908

25. National Heart, Lung, and Blood Institute, Task Force on Blood Pressure Control in Children (1987) Report of the Second Task Force on Blood Pressure Control in Children. Pediatrics 79:1-25

26. Wuhl E, Witte K, Soergel M, Mehls O, Schaefer F, German Working Group on Pediatric Hypertension (2007) Distribution of 24-h ambulatory blood pressure in children: normalized reference values and role of body dimensions. J Hypertens 20:1995-2007

27. Kavey R, Allada V, Daniels S, Hayman L, McCrindle B, Newburger J, Parekh R, Steinberger J (2006) Cardiovascular risk reduction in high-risk pediatric patients. Circulation 114:2710-2738

28. Furth S, Flynn J, Pierce C, Mitsnefes M, Wong C, Saland J, MoxeyMims M, Abraham A, Warady B (2010) Lower systolic BP associated with slower CKD progression in the CKiD study. J Am Soc Nephrol 21:551A

29. Chobanian A, Bakris G, Black H, Cushman W, Green L, Izzo J, Jones D, Materson B, Oparil S, Wright J, Roccella E (2003) The seventh report of the Joint National Committee on Prevention, Detection, Evaluation, and Treatment of High Blood Pressure. JAMA 289: 2560-2572

30. Renal Association Standards and Audit Subcommittee (2002) Treatment of adults and children with renal failure: standard and audit measures, 3rd edn. Royal College of Physicians of London and the Renal Association, London. Available at www.renal.org/guidelines

31. Sinaiko A (1996) Hypertension in children. N Engl J Med 335:19681973

32. Franscini L, Von Vigier R, Pfister R, Casaulta-Aebischer C, Fossali E, Bianchetti M (2002) Effectiveness and safety of the angiotensin II antagonist irbesartan in children with chronic kidney diseases. Am J Hypertens 15:1057-1063

33. Cook J, Daneman D, Spino M, Sochett E, Perlman K, Balfe J (1990) Angiotensin converting enzyme inhibitor therapy to decrease microalbuminuria in normotensive children with insulin-dependent diabetes mellitus. J Pediatr 117:39-45

34. Trachtman H, Gauthier B (1988) Effect of angiotensin-converting enzyme inhibitor therapy on proteinuria in children with renal disease. J Pediatr 112:295-298

35. Yuksel H, Darcan S, Kabasakal C, Cura A, Mir S, Mavi E (1998) Effect of enalapril on proteinuria, phosphaturia, and calciuria in insulin-dependent diabetes. Pediatr Nephrol 12:648-650

36. Sinaiko A, Kashtan C, Mirkin B (1986) Antihypertensive drug therapy with captopril in children and adolescents. Clin Exp Hypertens 8: 829-839

37. Tack E, Perlman J (1988) Renal failure in sick hypertensive premature infants receiving captopril therapy. J Pediatr 112:805-810

38. Pryde P, Sedman A, Nugent C, Barr M Jr (1993) Angiotensinconverting enzyme inhibitor fetopathy. J Am Soc Nephrol 3:15751582

39. Seeman T, Dusek J, Vondrak K, Flogelova H, Geier P, Janda J (2004) Ramipril in the treatment of hypertension and proteinuria in children with chronic kidney diseases. Am J Hypertens 17:415-420

40. Ellis D, Vats A, Moritz M, Reitz S, Grosso M, Janosky J (2003) Long-term antiproteinuric and renoprotective efficacy and safety of losartan in children with proteinuria. J Pediatr 143:89-97

41. Simonetti G, Rizzi M, Donadini R, Bianchetti M (2007) Effects of antihypertensive drugs on blood pressure and proteinuria in childhood. J Hypertens 25:2370-2376
42. Gartenmann A, Fossali E, von Vigier R, Simonetti G, Schmidtko J, Edefonti A, Bianchetti M (2003) Better renoprotective effect of angiotensin II antagonist compared to dihydropyridine calcium channel blocker in childhood. Kidney Int 64:1450-1454

43. The ONTARGET Investigators (2008) Telmisartan, ramipril, or both in patients at high risk for vascular events. N Engl J Med 358:15471559

44. Wong C, Pierce C, Cole S, Warady B, Mak R, Benador N, Kaskel F, Furth S, Schwartz G (2009) Association of proteinuria with race, cause of chronic kidney disease, and glomerular filtration rate in the Chronic Kidney Disease in Children study. Clin J Am Soc Nephrol 4: 812-819

45. Ardissino G, Vigano S, Testa S, Dacco V, Paglialonga F, Leoni A, Belingheri M, Avolio L, Ciofani A, Claris-Appiani A, Cusi D, Edefonti A, Ammenti A, Cecconi M, Fede C, Ghio L, Manna A, Maringhini S, Papalia T, Pela I, Pisanello L, Ratsch I (2007) No clear evidence of ACEi efficacy on the progression of chronic kidney disease in children with hypodysplastic nephropathy - report from the ItalKid Project database. Nephrol Dial Transplant 22:2525-2530

46. White C, Macpherson C, Hurley R, Matsell D (2003) Antiproteinuric effects of enalapril and losartan: a pilot study. Pediatr Nephrol 18: 1038-1043

47. Webb N, Shahinfar S, Wells T, Massaad R, Gleim G, Santoro E, Sisk C, Lam C (2012) Losartan and enalapril are comparable in reducing proteinuria in children. Kidney Int 82:819-826

48. Seeman T, Pohl M, Misselwitz J, John U (2009) Angiotensin receptor blocker reduces proteinuria independently of blood pressure in children already treated with angiotensin-converting enzyme inhibitors. Kidney Blood Press Res 32:440-444

49. Lubrano R, Soscia F, Elli M, Ventriglia F, Raggi C, Travasso E, Scateni S, Di Maio V, Versacci P, Masciangelo R, Romero S (2006) Renal and cardiovascular effects of angiotensin-converting enzyme inhibitor plus angiotensin II receptor antagonist therapy in children with proteinuria. Pediatrics 118:e833-e838

50. Moyer VA (2013) Screening for primary hypertension in children and adolescents: U.S. Preventive Services Task Force Recommendation Statement. Pediatrics 132:907-914

51. Shaughnessy A (2013) USPSTF: insufficient evidence to screen children and adolescents for hypertension. Daily POEMs. Wiley, New York. Available at www.essentialevidenceplus.com

52. Kavey R, Simons-Morton D, Jesus J (2011) Expert panel on integrated guidelines for cardiovascular health and risk reduction in children and adolescents: summary report. Pediatrics 128:S1-S44

53. Brady T, Redwine K, Flynn J, for the American Society of Pediatric Nephrology (2014) Screening blood pressure measurement in children: are we saving lives? Pediatr Nephrol 29:947-950

54. Daniels S, Gidding S (2013) Blood pressure screening in children and adolescents: is the glass half empty or more than half full? JAMA Pediatr 167:302-304

55. Yip G, Li A, So H, Choi K, Leung L, Fong N, Lee K, Li S, Wong S, Sung R (2014) Oscillometric 24-h ambulatory blood pressure reference values in Hong Kong Chinese children and adolescents. J Hypertens 32:606-619

\section{Answers}

1. a

2. $b$

3. d

4. c

5. c 